\title{
Characterization of Refined Rice Bran Wax: An Alternative Edible Coating
}

\author{
Panoth Abhirami and N. Venkatachalapathy* \\ Department of Food Engineering, Indian Institute of Food Processing Technology, \\ Thanjavur, India \\ *Corresponding author
}

\begin{abstract}
A B S T R A C T
\section{Keywords}

Edible coating; Rice bran wax; Refining; Value addition

Article Info

Accepted:

04 April 2019

Available Online:

10 May 2019

Edible wax coating is one of the method for enhancing the shelf life of fruits and vegetables, thereby post-harvest losses of these can also be reduced. India ranks first in the production of rice bran oil and large amount of wax available from the oil refineries. At present Indian scenario this wax is more used in pharmaceutical and cosmetics industries even though it is edible. Lack of proper refining method constraints its use in food application. In this present study refining of locally procured crude rice bran wax was done and its purity was checked by analyzing some physico chemical parameters. Variation in color, moisture content, melting point, acid value, iodine value and saponification value are observed as refining proceeds. The obtained results are accordance with previously reported values and similar to carnauba wax. The potential of crude wax in India can be wisely use for edible coating purposes which make value addition to the rice byproducts.
\end{abstract}

\section{Introduction}

India's diverse climate ensures the production of around 94 million metric tonnes of fruits and 182 million metric tonnes of vegetables and witness nearly $4.6-15.9 \%$ postharvest wastages of these perishables (NHB Statistics). Fruits and vegetables are perishables because of its higher moisture content. Constant loss of water occurs after their harvesting and eventually it leads to shriveling, poor texture and poor quality. Proper post-harvest treatments are necessary to minimize the water losses and to retain freshness of fruits and vegetables. The use of edible waxes can extend the shelf life of these perishables. Increasing demands of consumer for higher quality food in combination with the environment need to reduce the packaging wastes have led to the increased innovative researches in edible coating (Del-Valle et al., 2005). Rice bran wax is a hard yellowish to brownish wax obtained as a byproduct of dewaxing process in bran oil refining, composed of mixtures of fatty alcohol esters and fatty acids. It shows similar characteristics like carnauba wax and can serve as a substitute in fruits and vegetable coating (FDA $\S 172.890$ ). Rice bran wax is having a broad range of application in cosmetics, pharmaceutical purposes, electric insulations, textiles, waterproofing apart from food (Sanghi and Tiwle, 2015). At present its application in food is less even though Food 
and Drug Administration permits. Since rice bran wax is edible, cheap, stable, and having good film forming property, it can be used to preserve fruits and vegetables and having great future potential because of the higher production of the rice bran oil in India.

The study was conducted to refine the crude rice bran wax collected from local rice bran oil refinery and Characterization of the refined rice bran wax.

\section{Materials and Methods}

\section{Materials}

Crude rice bran wax with a brownish color was collected from a rice bran oil refinery in Thanjavur, Tamil Nadu. The collected crude wax was kept in ambient condition until it undergoes refining and further analysis. It is a waste material obtained from dewaxing process in bran oil refining and can be further utilized by value addition. Reports show that in India, rice bran wax is mostly used in cosmetics and to develop ointment bases.

\section{Methods of Refining}

Waxes are the esters of long chain carboxylic acid and long chain alcohol (Kolattukudy 1976). Wax content in rice bran oil may vary with oil extraction conditions such as the source of the rice bran, solvent used for extraction, temperature at which extraction occurs. Almost 3-4\% wax is present in rice bran oil on a total lipid basis. The composition of rice bran wax is not well known but some research studies are reported. In late 1960's a study shows that rice bran wax can be fractionated into hard wax and soft wax in which hard wax is a mixture of esters of $\mathrm{C}_{22}, \mathrm{C}_{24}$ and $\mathrm{C}_{34}$ fatty acids and the other contain $\mathrm{C}_{18}$ to $\mathrm{C}_{34}$ fatty alcohols (Iwama and Maruta, 1969). The amount of dark brown resin like material was observed in hard wax ( $\mathrm{C}_{16}$ to $\mathrm{C}_{26}$ fatty acids) as well as in soft wax with $\mathrm{C}_{22}$ to $\mathrm{C}_{30}$ fatty alcohols (Yoon and Rhee 1982) and the presence of branched chain aliphatic $\mathrm{C}_{32}, \mathrm{C}_{34}, \mathrm{C}_{36}$ fatty alcohol esters in rice bran wax was reported by (Ito $e t$ al., 1983). Hongsun (1998) confirmed the presence of $\mathrm{C}_{22}$ to $\mathrm{C}_{38}$ fatty acids and $\mathrm{C}_{14}$ to $\mathrm{C}_{38}$ fatty alcohols in refined rice bran wax. Unevenness in these reports is mainly due to the lack of proper refining methods. Overall the composition of crude wax includes oil of $20-70 \%$, free fatty acids of $0-20 \%$, wax of 25-65\%and resinous matter of 5-12\% (Global Rice Bran oil conference, 2015). In order to obtain pure wax other contaminants like resinous matter, oil, free fatty acids should be removed. This is why refining of crude wax is really important.

Refining of crude wax involves 3 steps

\section{Defatting}

The oil content (20-70\%) of rice bran wax was removed by defatting method. Normal soxhlet apparatus can be used for this process but in this study we preferred conventional soxhlet apparatus for defatting more amount of sample. $100 \mathrm{~g}$ of crude wax was taken in a round bottom flask which is connected to a reflux condenser.

This crude wax was refluxed with $700 \mathrm{ml}$ of hexane for 90 minutes at $69^{\circ} \mathrm{C}$. The content was kept for cooling and later it filtered off. This residues $(50 \mathrm{~g})$ was again refluxed with $350 \mathrm{ml}$ of isopropanol for further extraction of oil at $85^{\circ} \mathrm{C}$ for $45 \mathrm{~min}$, Thus oil content is removed from the crude wax (Vali et al., 2005).

\section{Bleaching}

Resinous materials present in the defatted wax could be removed by bleaching. Defatted wax of $25 \mathrm{~g}$ was put in a two necked round 
bottom flask in which one neck is closed with rubber septum. A reflux condenser is fitted at the other neck of the flask. This content is refluxed with $175 \mathrm{ml}$ of isopropanol for 45 min at $85^{\circ} \mathrm{C} .10 \%$ Sodium borohydride solution was prepared by adding $10 \mathrm{ml}$ of distilled water to $0.5 \mathrm{~g}$ of sodium borohydride crystals. This solution is added to the refluxing content with the help of a syringe through the rubber septum over a period of 15-20 minutes. A reddish brown color resinous material was appeared during the addition of sodium borohydride solution. Reflux action should be continued for another 70-80 minutes followed by cooling the contents to ambient temperature (Vali et al., 2005).

\section{Filtration}

The cooled contents were filtered by using membrane filtration assembly with the help of vacuum and allowed to dry in shade. The filtered cake was washed with isopropanol and then with distilled water to remove the odor of isopropanol. After drying an odorless light yellow fine powder were yielded. This can be further utilized for edible coating preparation (Vali et al., 2005).

The refined rice bran wax has undergone for several physical and chemical analysis for the characterization purposes

\section{Analysis}

\section{Color}

The color of the crude rice bran wax and the refined rice bran wax was obtained by using Hunter color lab instrument. The results were analyzed by comparing the change in color from dark brown to light yellow. Total color change was found by the given equation.

$$
\Delta \mathrm{E}=\sqrt{ }(L o-L) 2+(a o-a) 2+(b o-b) 2
$$

\section{Moisture content}

The Moisture content of the sample was found by using hot air oven method (AOAC 1995 ) at $105^{\circ} \mathrm{C}$ for 1 hour and it is found by the ratio of the difference between initial and final weight in gram to the initial mass in gram.

\section{Melting point}

The Melting point of a compound indicates the temperature at which the phase changes from solid to liquid. This is one of the parameter used to check the purity of compound. In this study the melting point of rice bran wax was found by using capillary tube method (Hartman and Lago, 1973) (AOAC, 2000).

\section{Acid value}

Acid value represents the number of milligrams of $\mathrm{KOH}$ required to neutralize free fatty acid content which is present in $1 \mathrm{~g}$ of fat. The followed procedure involves the titration of against $0.1 \mathrm{~N} \mathrm{KOH}$ with phenolphthalein indicator (AOAC, 2000).

\section{Iodine value}

The amount of unsaturation in refined wax was found by measuring the iodine value. It is a number which indicate the amount of iodine in gram absorbed by $100 \mathrm{~g}$ of wax by using Wijs solution. This was done by referring (AOAC 2000) norms.

\section{Saponification value}

It is a value which indicates the amount of potassium hydroxide in $\mathrm{mg}$ required to saponify one gram of fat or wax and this number is an index of mean molecular weight of fatty acids of glycerides present in wax. This was found using AOAC 2000 method. 


\section{Results and Discussion}

The collected crude rice bran wax was refined by three steps of defatting, bleaching and filtration. The characterization of refined wax was done with 6 parameters.

A substantial color change was observed to the crude wax after refining (Figure 1). The color was changed from brown to light yellow color. $\Delta \mathrm{E}$, total color change was found as 21.91 and 11.32 between crude wax to defatted and defatted to refined wax respectively as per the afore mentioned equation. The gradual increase in $\mathrm{L}^{*}$ value shows increase in lightness and the reducing trend of $\mathrm{a}^{*}$ indicates the decrement in red color and the positive $b^{*}$ implies the yellow color. The appeal of rice wax matters while taking it for edible coating. The color change is due to the removal of resinous materials present in the wax.

The moisture content in wax is found to be decreasing from $0.109 \%$ to $0.075 \%$ when it gets defatted. This loss of moisture may be due to the continuous reflux action with hexane and isopropanol. But the trend is different when coming to refined wax, the moisture content is raised from $0.075 \%$ to $0.11 \%$ and it may be due to washing the refined wax with distilled water at the end of the process (Fig. 2-4 and Table 1).

Table.1 Physico chemical characteristics of crude wax, defatted wax and refined wax

\begin{tabular}{|c|c|c|c|}
\hline PARAMETERS & CRUDE WAX & DEFATTED WAX & REFINED WAX \\
\hline COLOR & Dark brown & Light brown & Light Yellow \\
\hline MELTING POINT $\left({ }^{\circ} \mathbf{C}\right)$ & 64.00 & 78.00 & 80.50 \\
\hline MOISTURE CONTENT $(\boldsymbol{\%})$ & 0.11 & 0.08 & 0.12 \\
\hline ACID VALUE & 29.49 & 4.71 & 2.59 \\
\hline IODINE VALUE & 37.06 & 15.22 & 6.59 \\
\hline SAPONIFICATION VALUE & 142.62 & 95.18 & 89.76 \\
\hline
\end{tabular}

Fig.1 Color changes at different stages of refining

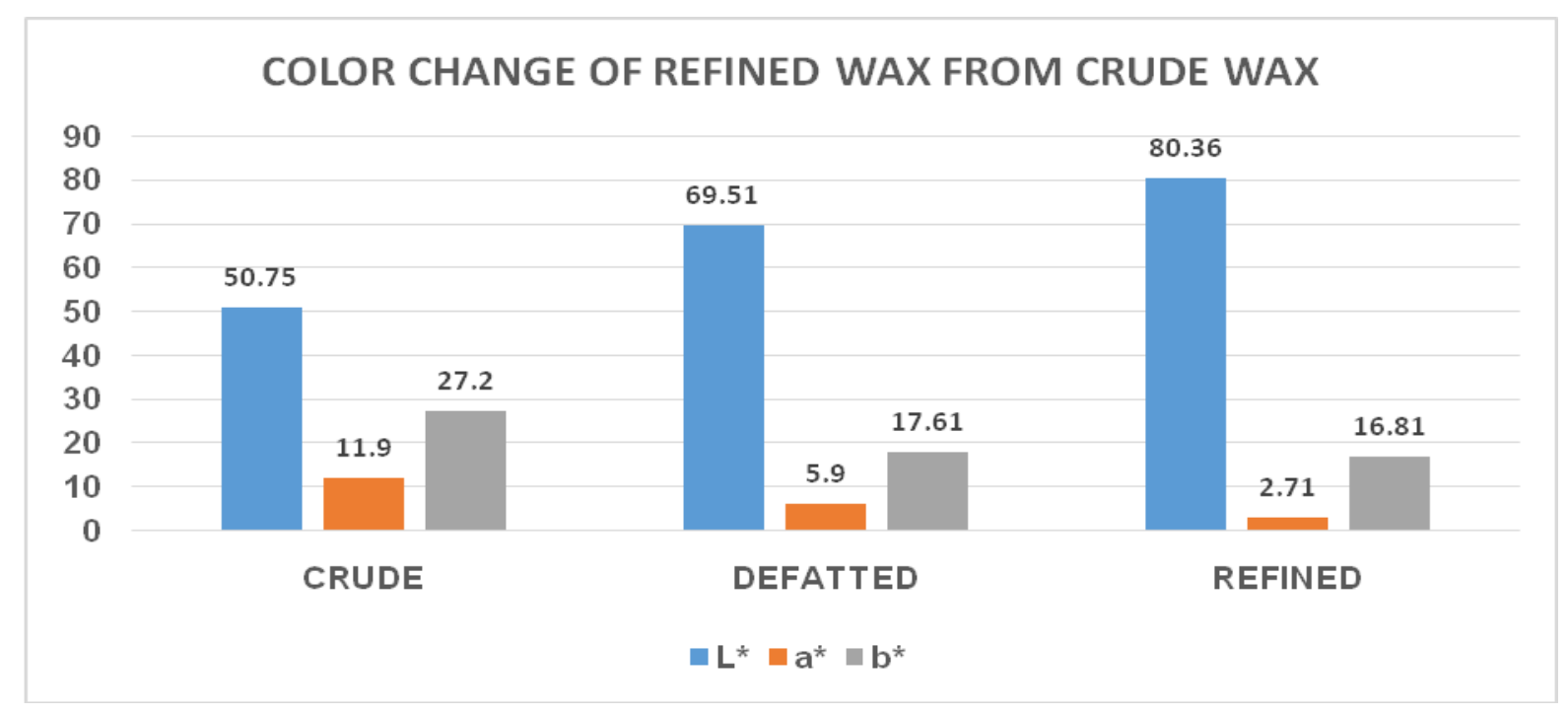


Fig.2 Moisture content present in different types of wax

\section{MOISTURE CONTENT}

0.14

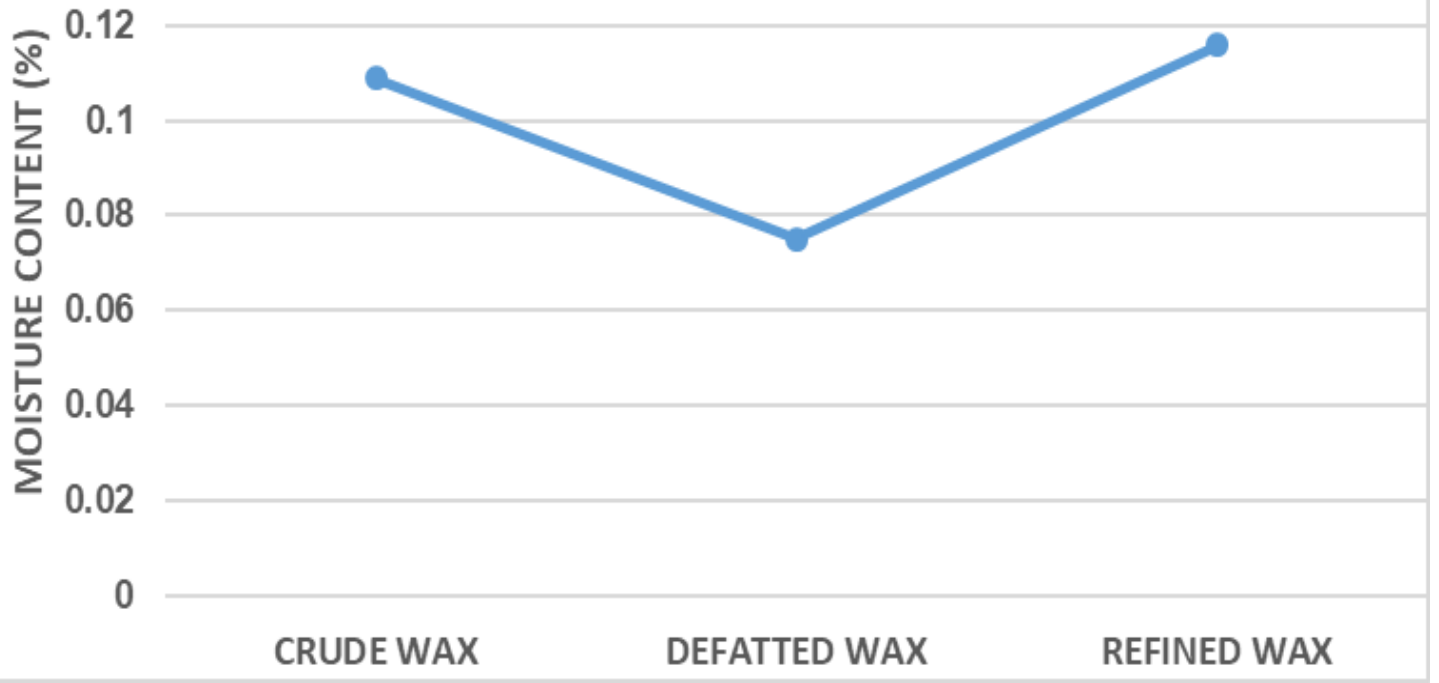

Fig.3 Changes in acid value and iodine value during refining

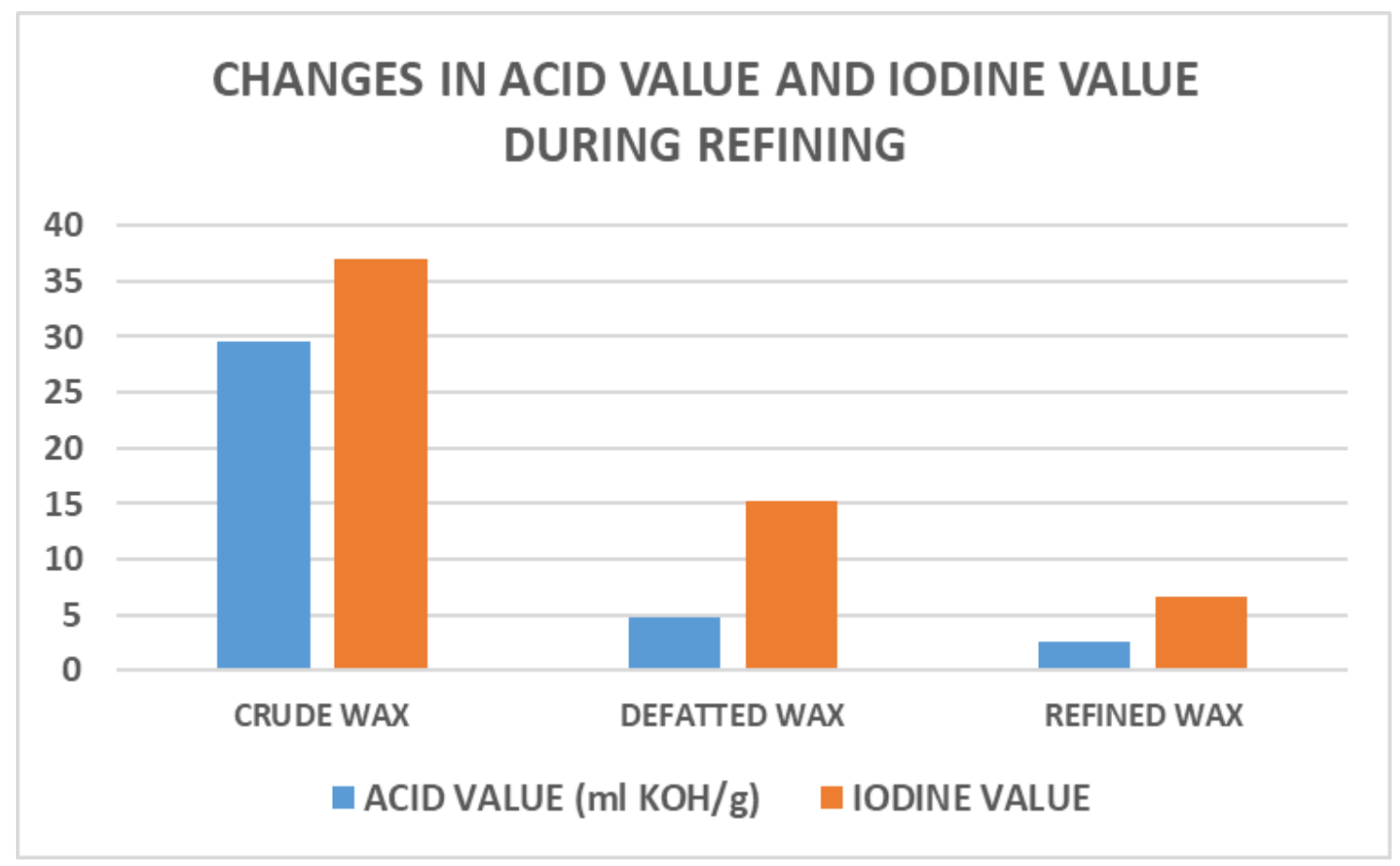


Fig.4 Changes in melting point and saponification value during refining

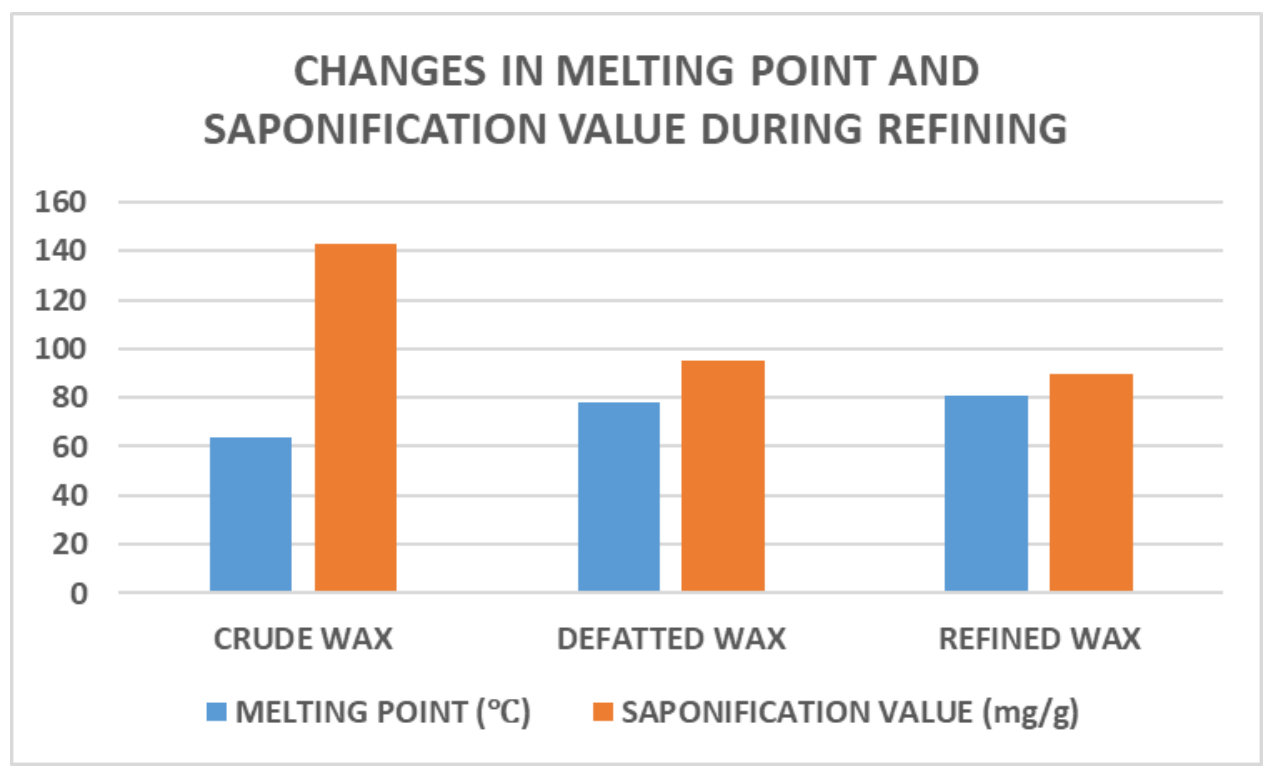

Acid value is decreasing as refining proceeds which indicates the crude wax is less stable than the refined wax. During refining process, the amount of resinous materials, fatty acids are removed and this may be the reason of decreasing trend of acid value.

Iodine value is used to measure the unsaturation in fats or waxes. The trend of iodine value as well as saponification value shows a reduction during refining. Since crude wax is having higher iodine value, it is having higher degree of unsaturation than the refined wax.

The results of melting point showed a rapid increase with increase in degree of purity. The melting point of crude wax was found to be $64^{\circ} \mathrm{C}$ while that of refined wax was $80.5^{\circ} \mathrm{C}$. This higher melting point of refined wax may help in edible coating emulsion preparation and further coating.

Saponification value is related with molecular weight of the fat present. The decreasing trend of saponification value shows that the molecular weight of fats is also decreasing during refining.
In conclusion, the method described in this article is one of the efficient method of refining crude wax at laboratory scale with high purity and the values of parameters checked are come accordance with the reported values within the range. This refined wax can be further utilized for preparing edible coating for the shelf life extension of perishables. India is one among the largest producer of rice bran oil and the potential for the rice bran wax is very high. Since it is having edible property apart from other aesthetic and pharmaceutical application, this can be used as value addition to the rice byproducts and this study can be used for further investigation for making edible coating for fruits and vegetables in order to reduce the huge post-harvest loss of perishables.

\section{Recommendations}

The high potential of the raw material availability in India can lead to do more researches in Rice wax in order to increase the value addition and byproduct utilization of rice bran oil refineries in food allied areas. 


\section{Acknowledgement}

We thank IIFPT, Thanjavur for providing all lab facilities and food grade chemicals required for this study.

\section{References}

Del-Valle, V., Hernández-Muñoz, P., Guarda, A and Galotto, M. J. 2005. Development of a cactus-mucilage edible coating (Opuntiaficus indica) and its application to extend strawberry (Fragaria ananassa) shelflife.Food Chem. 91(4): 751-756.

Food and Drug Administration § 172.890

Hartman, L. and Lago, R.C. 1973. Rapid preparation of fatty acid methyl esters from lipids.Lab Pract. 22(6): 475-476.

Hongsun, W. Y. N. P. D. 1998. Composition of Rice Bran Wax [J]. China oils and fats. Pp. 6.

Ito, S., Suzuki, T., Fujino, Y. 1983. Wax lipid in rice bran. Cereal. Chem, 60: 252-253.
Iwama, F. and Maruta, S 1969. Composition of the Hard Portion of Crude Rice Bran Wax. Kogyo Kagaku Zasshi. 72: 2605-2608.

Kolattukudy, P. E. 1976. Chemistry and biochemistry of natural waxes. Elsevier Scientific Pub. Co.

National Horticulture Board Statistics 2017

Vali, S. R., Ju, Y.H., Kaimal, T.N.B., and Chern,Y.T.2005. A process for the preparation of food-grade rice bran wax and the determination of its composition. J Am Oil Chem Soc., 82(1): 57-64.

Vandenburg, L. and Wilder, E.1970. The structural constituents of carnauba wax.J Am Oil Chem Soc.47(12): 514518.

Sanghi, D.K., Tiwle, R. 2015. A review of comaparitive study of rice bran oil and rice bran wax.Int. J Pharm Sci Rev Res.5(4):403-410.

Yoon, S. and Rhee, J. S.1982. Composition of waxes from crude rice bran oil.J Am Oil Chem Soc. 59(12): 561-563.

\section{How to cite this article:}

Panoth Abhirami and Venkatachalapathy, N. 2019. Characterization of Refined Rice Bran Wax: An Alternative Edible Coating. Int.J.Curr.Microbiol.App.Sci. 8(05): 91-97. doi: https://doi.org/10.20546/ijcmas.2019.805.012 